\title{
Potential of robots as next-generation technology for clinical assessment of neurological disorders and upper-limb therapy
}

\author{
Stephen H. Scott, PhD; ${ }^{{ }^{*}}$ Sean P. Dukelow, MD, $\mathbf{P h D}^{\mathbf{2}}$ \\ ${ }^{1}$ Centre for Neuroscience Studies, Department of Anatomy and Cell Biology and Department of Medicine, Queen's \\ University, Kingston, Canada; ${ }^{2}$ Department of Clinical Neurosciences, University of Calgary, Calgary, Canada
}

\begin{abstract}
Robotic technologies have profoundly affected the identification of fundamental properties of brain function. This success is attributable to robots being able to control the position of or forces applied to limbs, and their inherent ability to easily, objectively, and reliably quantify sensorimotor behavior. Our general hypothesis is that these same attributes make robotic technologies ideal for clinically assessing sensory, motor, and cognitive impairments in stroke and other neurological disorders. Further, they provide opportunities for novel therapeutic strategies. The present opinionated review describes how robotic technologies combined with virtual/augmented reality systems can support a broad range of behavioral tasks to objectively quantify brain function. This information could potentially be used to provide more accurate diagnostic and prognostic information than is available from current clinical assessment techniques. The review also highlights the potential benefits of robots to provide upper-limb therapy. Although the capital cost of these technologies is substantial, it pales in comparison with the potential cost reductions to the overall healthcare system that improved assessment and therapeutic interventions offer.
\end{abstract}

Key words: augmented reality, clinical assessment, cognitive function, movement disorders, rehabilitation, robotics, sensorimotor function, stroke, upper limb, virtual reality.

\section{INTRODUCTION}

Over the last 100 years, radical changes have occurred in the assessment and treatment of disease.
Blood tests now provide a wealth of information on the function of many organs, genetic testing can predict some diseases, and imaging techniques provide detailed quantitative information on the anatomical structure of the body. Substantial changes have also occurred in the treatment of disease. These include advances in pharmacological interventions and biomedical devices such as cardiac pacemakers, prosthetic limbs, and cochlear implants to ameliorate the effects of dysfunction. These advances reflect the transfer of knowledge and increased use of technology from basic research to clinical practice.

Not all fields of medicine have been equally influenced by technology. With the exception of advances in structural and functional imaging, neurological assessment is still largely based on a clinician's perceptual decisions when monitoring the behavioral performance of the patient, such as testing the briskness of the muscle stretch reflex with a hammer tap or observing the range

\footnotetext{
Abbreviations: ADL $=$ activity of daily living, FIM $=$ Functional Independence Measure, FM = Fugl-Meyer, MIME = Mirror Image Motion Enabler, MRC = Medical Research Council, MRI = magnetic resonance imaging.

*Address all correspondence to Stephen $\mathbf{H}$. Scott, PhD; Centre for Neuroscience Studies, Queen's University, Botterell Hall, Room 219, Kingston, Ontario, Canada, K7L 3N6; 613-533-2855; fax: 613-533-6840.

Email: steve@biomed.queensu.ca

DOI:10.1682/JRRD.2010.04.0057
} 
of motion and movement of a joint. This reliance on subjective assessment tools reflects the keen ability of the human perceptual system to observe even subtle differences between normal and abnormal behavior and the difficulty to develop technologies to replicate this ability of human observation. Although assessment tools have evolved to quantify sensory, motor, and cognitive deficits using clinician-based measurement systems, these approaches remain inherently subjective.

Correspondingly, rehabilitation approaches for neurological disorders such as for stroke or traumatic brain injury remain largely based on one-on-one interactions between patient and therapist. Rehabilitation approaches vary widely across practitioners with little evidence to support why one approach is better than another [1-3].

The result is a vicious circle between neurological assessment and neurorehabilitation: the lack of sensitive tools to quantify dysfunction makes demonstrating the effectiveness of novel therapeutic approaches difficult, and limited improvement by existing treatments as measured by current assessments implies no need for better assessment tools.

Our purpose with this review is to suggest that the time may be right for a profound change in neurological assessment and neurorehabilitation, particularly related to stroke and traumatic brain injury. Our hypothesis is that robotic technologies can provide a radically new and effective approach to clinical assessment of brain function and rehabilitation. This approach also takes advantage of advances in our understanding of brain function to develop a range of behavioral tasks to assess the various brain circuits that support sensory, motor, and cognitive function. As well, it highlights how these same technologies can be used for rehabilitation in subjects following stroke.

Over the last 40 years, our understanding of how the brain supports sensory, motor, and cognitive function has substantially increased [4-5]. Behavioral studies on humans have identified how we use sensory input to the brain to perceive the world around us, make decisions, and guide our highly skilled and flexible motor actions. Anatomical tracing techniques highlight the anatomical connectivity among different brain regions. Neurophysiological studies in awake, behaving animals have uncovered how neural activity in various brain regions correlates with various sensory, motor, and cognitive functions. In turn, clinical research on various patient groups have highlighted how damage in even small por- tions of the brain can have a profound impact on brain processing.

The culmination of these studies forms several basic principles about brain function. First, sensory and motor systems work together to permit us to move and interact in the environment and create our perception of the world. Our perception is generated by the integration of the various sensory modalities and is heavily influenced by prediction and previous experience [6-7]. Our motor system is highly adaptable [5,8], permitting us to perform a broad range of motor skills, including tool use. We can flexibly hold a pen to write a letter or use both hands cooperatively to open a jar. Additionally, we have a range of capabilities broadly defined as cognition that help us interpret the world, generate abstract reasoning, and decide how we should move and interact in the environment.

Second, a given function is supported by a highly distributed network in the brain. A relatively simple task such as visually guided reaching requires many cortical and subcortical regions of the brain to identify, initiate, and correctly move the hand to a spatial goal $[5,9]$. Further, a given region of the brain plays a unique yet overlapping role for a given behavior. Neurons in several parietal and frontal motor regions are active during the execution of a reaching movement. However, the activity reflects different aspects of the task with posterior parietal and premotor motor regions activity correlated to more spatial aspects of the task, and primary motor cortex activity correlated to more motor aspects of the task such as limb geometry and muscle forces [10].

Third, the ability to perform sensory, motor, and cognitive functions requires substantial learning so that brain processing is highly plastic and altered by experience [11-13]. Different regions of the brain use different forms of learning [14]. Injury to the brain alters its normal processing, for which the brain can completely or partially compensate through adaptation and learning processes. However, in some cases, these changes can be maladaptive, such as spasticity [15] or neuropathic pain syndromes [16] following stroke.

Our improved understanding of how the brain supports sensory, motor, and cognitive functions is directly linked to the use of advanced technologies to quantify brain signals, control sensory input to the brain, and monitor and modify body movement. Brain activity such as electroencephalography or functional magnetic resonance imaging (MRI) can be used to quantify brain processing. As well, computer monitors and virtual or augmented 
reality systems are commonly used to control visual stimuli for perceptual or motor tasks. Finally, body movement is quantified using a host of devices including robots, motion-tracking systems, and eye-tracking technologies.

This improved understanding of brain function also reflects substantial advances in theoretical and computational approaches for interpreting brain function. Bayesian inference and economic theories provide formal computational frameworks for understanding perceptual and cognitive decision making [7,17-18], and optimal control theory illuminates the flexible nature of the voluntary motor system shaped by evolution and learning [19-20]. Admittedly, we are far from a final description on the complexities of brain processing. However, basic research provides a wealth of concepts and technologies that can be used to interpret brain dysfunction [21], but, as described in the following, have yet to adequately affect clinical assessment and rehabilitation related to the brain.

\section{CLINICAL ASSESSMENT OF STROKE}

\section{Traditional Approaches}

Clinical assessment of stroke has classically aimed at measuring either neurological impairment or disability. Impairment generally denotes how a particular function of the brain has been altered (e.g., ability to see), whereas disability denotes the ability of someone to perform activities of daily living (ADLs) (e.g., grooming). Although ADLs are of major importance for understanding how an individual can cope in the world following stroke, identifying that someone cannot perform an ADL tells us little about why they cannot perform it. Ideally, the goal of rehabilitation is to reestablish brain function, and thus it is essential to identify the neurological impairments to meet this objective.

Many different brain functions can be assessed, of course. Some measures of motor function were initially designed for lower motor neuron disorders, such as the Medical Research Council (MRC) Scale for Motor Power [22], and do not account for the various synergy patterns that are observed in patients with stroke. Assessment of strength is relatively crude, with the vast majority of patients who exhibit weakness ( 96\%) being grade 4 of 5 [23]. Assessment tools have been developed specifically for quantifying the effects of stroke such as the Chedoke-McMaster Stroke Assessment (Chedoke Assessment) [24] and the Fugl-Meyer (FM) test [25]. In many respects, these scales often mix measurement of impairment (i.e., ability to raise the arm) and disability (i.e., pouring water into a glass).

Although many stroke rehabilitation assessment protocols are "standardized and validated," most rely on an examiner, typically the treating clinician, to make judgments regarding the patient's performance (e.g., Chedoke Assessment [24,26], Functional Independence Measure [FIM] [27], FM [25]). The observer typically scores the patient's performance on an ordinal or ordered categorical scale (e.g., MRC Scale for Motor Power [scored 1-5]) [22] and determining if a patient is actually improving on the ordinal scale can be difficult. Additionally, these scales are deemed "reliable" because they offer the user so few options (numbers) to choose from. This introduces potential observer bias and results in tools that are not sensitive to subtle but clinically important functional changes.

Further, many of the tools currently used have documented problems with floor or ceiling effects (e.g., FM [25]) and rely on criteria rather than normal value reference standards (e.g., Chedoke Assessment, FIM, FM). Lastly, many assessments can take a long time to complete (e.g., Behavioral Inattention Test [28]). In our experience, this leads clinicians to either delay the delivery of treatment in favor of a lengthy assessment (in some cases as long as 5 days), despite evidence on the timing and importance of early rehabilitation treatment [29-33], or abandon assessment altogether.

Some research-oriented tools, such as the Wolf Motor Function Test, use a time-based score, requiring patients to perform a number of basic motor actions [34]. This alleviates the coarseness in the rating system and the ceiling effects, but the test does not allow for explanation of why a patient may have needed more time.

Most of the assessment tools just described above are weighted toward exploring motor impairments and function. Proprioception is defined as the perception of position, motion, and force generated by the body based on sensory information from muscle spindles, Golgi tendon organs, joint and cutaneous receptors, and efference copy of motor commands [35-37]. Sherrington proposed that proprioception was made up of two subcomponentsposition sense and kinesthesia [38]. Position sense is a person's awareness of the relative position of body segments [38]. Kinesthesia is the sense that a body part has moved [38]. 
Clinicians commonly assess position sense based on the ability of a patient to accurately discriminate the upward or downward position of a finger and/or toe [39]. Occasionally, more proximal single joints may also be tested in this manner [40]. Some clinicians use the thumb-localizing test [41]. Reports indicate that approximately one-third to one-half of patients with stroke have impaired position sense [42-43]. While position sense is only one component of proprioception, its importance is highlighted by reports that intact position sense following stroke strongly correlates with motor recovery of the hemiplegic arm [44-48] and predicts the extent of longterm motor recovery [45].

Assessment of sensation related to mechanosensation and muscle afferents is relatively poor. A recent study concluded that the FM sensation subscale could not be recommended for clinical use because it showed significant ceiling effect and low validity and responsiveness to clinically meaningful change [49]. The ceiling effect implies that many patients attain full score without necessarily having intact sensation. These clinical tools, however, have very poor interrater reliability $[40,50]$ and have been criticized for having poor sensitivity and poor or absent normal value criteria [40,50-51].

A good clinical assessment tool should possess several important attributes. First, it should be objective based on continuous, normative scales of typical behavior with no floor or ceiling effects. The measure should possess various aspects of validity, including face (looks like it measures what it is meant to measure) and content (covers a representative sample or areas of a domain). The tool also needs to be reliable both within and between observers. Further, an ideal tool would be fairly rapid to administer and widely available. Finally, the measure should be both sensitive (proportion of actual positives correctly identified) and specific (proportion of negatives correctly identified).

Present clinical assessment tools use ordinal scales to focus on what could be termed relatively low-level aspects of motor function. Measures of strength, tone, muscle stretch reflexes, range of motion, and basic motor coordination are performed, in part, because they can be measured during a physical examination. However, many obvious signs of motor impairments, such as slowed response times or the degree of clumsiness interacting with the environment, are more difficult to quantify on a physical examination.

In some ways, the current clinically used assessment tools represent the tip of the iceberg. For example, strokes that affect the sensorimotor cortex result in diminished long-latency responses and delayed voluntary responses [52]. These reflexes are not the typical muscle stretch reflexes elicited with a tendon hammer during a standard neurological examination. Instead, these longlatency reflexes represent rapid motor responses that can be modified based on behavioral context and are thought to provide a crucial part of how one generates highly coordinated voluntary motor actions [20]. Subjects with stroke can also show subtle yet measurable differences in performance such as differences in reaction time during reaching between their paretic and nonparetic limbs [53]. Easily and accurately quantifying these features of the sensorimotor system with a standard clinical examination is nearly impossible. What is needed is an approach that can get at these more complex yet important aspects of sensorimotor function.

\section{Rationale for Robotic Assessment}

One relatively basic feature of robots is that they can be used as a measurement device to quantify limb motion. Essentially, two types of robotic technologies have been used to study whole-limb function (Table). Exoskeleton robots parallel the motion of the body segments so that the joints of the robot are aligned with the joints of the subject wearing the device. They can provide a wealth of information on both hand and joint motion during behavior. Systems can be designed to support the weight of the limb, potentially valuable for removing the effects of fatigue or muscle weakness. End point robots can be grasped by the subject's hand, permitting tracking of hand motion. They provide less information on limb motion but tend to be less expensive and easier to operate than exoskeleton robots. They can be modified to attach the hand with a brace to support the limb. In either case, how the subject moves the robot provides a robust measure of limb motion.

Another obvious value of robots is their capability to control limb movement. These technologies can move a limb through a specified trajectory or permit free limb movement and apply discrete mechanical perturbations or even simulate the properties of the environment such as contact with a rubber ball. It is this combined measurement and control that makes robots a versatile tool for studying upper-limb function.

Robots can be designed in a range of sizes and complexities. They can be relatively simple to monitor and control a single direction of movement at a single 
Table.

Robotic technologies for therapy and/or assessment of upper-limb function.

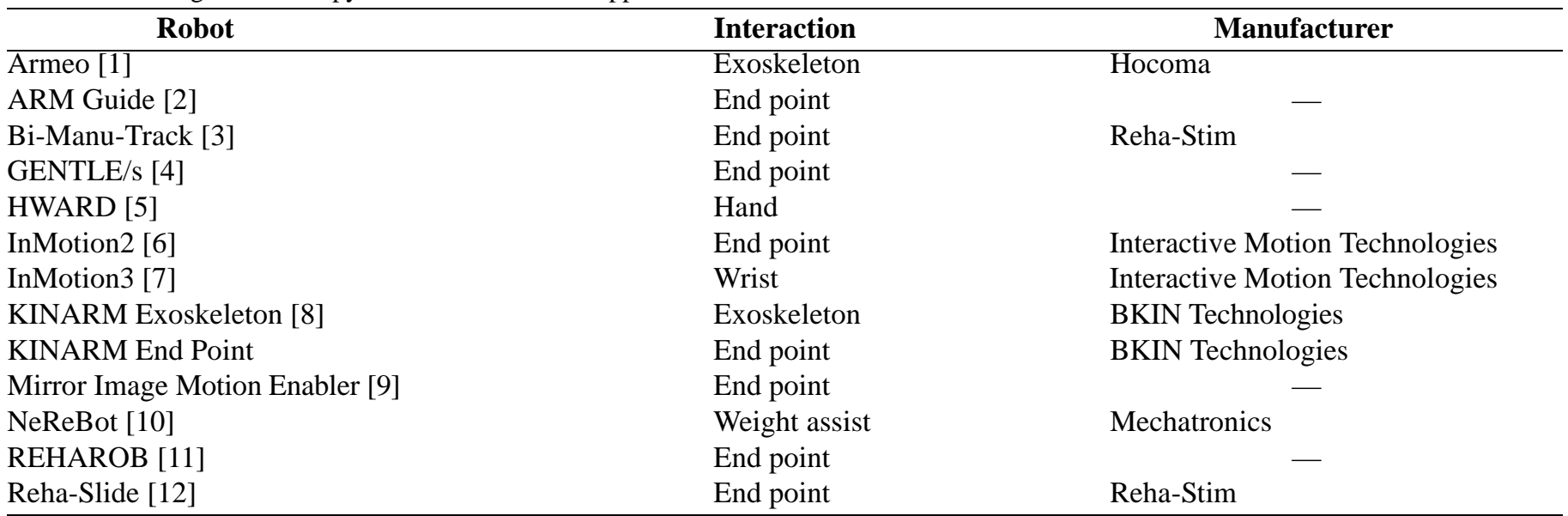

1. Riener R, Nef T, Colombo G. Robot-aided neurorehabilitation of the upper extremities. Med Biol Eng Comput. 2005;43(1):2-10. [PMID: 15742713] DOI:10.1007/BF02345116

2. Reinkensmeyer DJ, Kahn LE, Averbuch M, McKenna-Cole A, Schmit BD, Rymer WZ. Understanding and treating arm movement impairment after chronic brain injury: Progress with the ARM Guide. J Rehabil Res Dev. 2000;37(6):653-62. [PMID: 11321001]

3. Hesse S, Schulte-Tigges G, Konrad M, Bardeleben A, Werner C. Robot-assisted arm trainer for the passive and active practice of bilateral forearm and wrist movements in hemiparetic subjects. Arch Phys Med Rehabil. 2003;84(6):915-20. [PMID: 12808550] DOI:10.1016/S0003-9993(02)04954-7

4. Coote S, Murphy B, Harwin W, Stokes E. The effect of the GENTLE/s robot-mediated therapy system on arm function after stroke. Clin Rehabil. 2008;22(5): 395-405. [PMID: 18441036] DOI:10.1177/0269215507085060

5. Takahashi CD, Der-Yeghiaian L, Le V, Motiwala RR, Cramer SC. Robot-based hand motor therapy after stroke. Brain. 2008;131(Pt 2):425-37. [PMID: 18156154] DOI:10.1093/brain/awm311

6. Krebs HI, Hogan N, Aisen ML, Volpe BT. Robot-aided neurorehabilitation. IEEE Trans Rehabil Eng. 1998;6(1):75-87. [PMID: 9535526] DOI:10.1109/86.662623

7. Krebs HI, Volpe BT, Williams D, Celestino J, Charles SK, Lynch D, Hogan N. Robot-aided neurorehabilitation: A robot for wrist rehabilitation. IEEE Trans Neural Syst Rehabil Eng. 2007;15(3):327-35. [PMID: 17894265] DOI:10.1109/TNSRE.2007.903899

8. Dukelow SP, Herter TM, Moore KD, Demers MJ, Glasgow JI, Bagg SD, Norman KE, Scott SH. Quantitative assessment of limb position sense following stroke. Neurorehabil Neural Repair. 2010;24(2):178-87. [PMID: 19794134] DOI:10.1177/1545968309345267

9. Burgar CG, Lum PS, Shor PC, Machiel Van der Loos HF. Development of robots for rehabilitation therapy: The Palo Alto VA/Stanford experience. J Rehabil Res Dev. 2000;37(6):663-73. [PMID: 11321002]

10. Masiero S, Celia A, Rosati G, Armani M. Robotic-assisted rehabilitation of the upper limb after acute stroke. Arch Phys Med Rehabil. 2007;88(2):142-49. [PMID: 17270510] DOI:10.1016/j.apmr.2006.10.032

11. Fazekas G, Horvath M, Troznai T, Toth A. Robot-mediated upper limb physiotherapy for patients with spastic hemiparesis: A preliminary study. J Rehabil Med. 2007;39(7):580-82. [PMID: 17724559] DOI:10.2340/16501977-0087

12. Hesse S, Schmidt H, Werner C, Rybski C, Puzich U, Bardeleben A. A new mechanical arm trainer to intensify the upper limb rehabilitation of severely affected patients after stroke: Design, concept and first case series. Eura Medicophys. 2007;43(4):463-68. [PMID: 18084168]

joint, or they can permit free movement of the limb in three-dimensional space. However, clear trade-offs exist between the complexity of the measured behavior and the complexity of the technology and associated analyses. Planar paradigms are often chosen because they provide a pragmatic balance between behavioral and technological complexity.

Robots are typically combined with visual presentation systems. These can be as simple as a computer moni- tor to display visual targets with a circle to denote the robot-based feedback of limb position. Robots can be easily paired with virtual reality systems so that visual stimuli and a rendering of the limb can be displayed in the actual workspace. Augmented reality permits the limb to be viewed directly along with projected visual stimuli [54]. Both virtual and augmented reality systems permit a natural registration between visual and proprioceptive feedback during motor performance. 


\section{Robots for Upper-Limb Motor Assessment}

Robotic devices could be used to quantify features of the motor system classically assessed during the neurologic physical examination: strength, muscle stretch reflexes, spasticity/tone, range of motion, and basic motor coordination. The capability of robots to apply discrete perturbations make them ideal for quantifying reflexive behavior and, notably, exploring more complex long-latency responses that cannot be elicited with a hammer tap [55]. For example, a recent study using robots to apply multijoint perturbations of the arm highlighted how patterns of muscle activity tend to generate multijoint flexor synergies in subjects with stroke [56].

An interesting use of robots has recently been developed by Ellis et al., in which they quantified the range of motion of upper-limb function by having subjects create a limb movement to trace the region of space that a subject could move their arm [57]. With the robot providing full weight support of the limb, many subjects could move their limb through a large region of space. They then asked subjects to perform the same task as the robot provided less and less weight support. The result was a greatly diminished range of motion, demonstrating the important coupling between active range of motion and weight support.

However, several challenges remain to replicating some existing assessment approaches. First, using robots to assess all joints across all of their mechanical degrees of freedom with a single robotic device would be difficult. One possibility is to design systems that quantify several joints but only for a single degree of freedom (i.e., shoulder, elbow, and wrist flexion/extension along with rudimentary grasp). Alternatively, one could use two separate robots, one that quantifies the proximal arm and a second system that quantifies hand and wrist function.

Second, measures of strength, particularly for the shoulder and elbow joints, would require very large motors on the robot, resulting in a very bulky robot with high friction, negatively affecting its capability to perform subtle tasks, in which the robot is meant to minimally intervene in limb movement. Instead of strength, measures of maximal speed to perform a movement may be more useful because normally a strong coupling should exist between speed and strength [58].

Perhaps the greatest potential for robots is realized when one thinks beyond traditional clinical measures of motor function. Robots, when combined with virtual or augmented reality systems, have an enormous control of the visual and somatosensory systems and can precisely monitor motor output at a very rapid rate, which makes them ideal for studying a broad range of sensory, motor, and cognitive functions.

Two studies recently used robots to quantify the ability of subjects with stroke to make visually guided reaching movements $[53,59]$. This task requires the individual to maintain the hand at an initial visual target, then identify the onset and location of another visual stimuli, and then initiate and complete a movement to this second spatial goal. This task requires participation of a neural circuit that spans the occipital, parietal, and frontal lobes, as well as subcortical structures such as the cerebellum $[5,9]$. The distributed circuit involved in visually guided reaching makes the task a relatively "dirty" one, in that impairments in the task may reflect deficits or injury across many brain regions. Reaching performance in this task, however, is highly correlated with ADL scores such as FIM [59-60].

Figure 1 illustrates the spatial pattern of hand movements for a control and two subjects with stroke [53]. One of the key advantages of robot-based assessments is that a wealth of information can be gathered during a single behavior. We nominally identified five groups of parameters to characterize reaching movements: postural control, visual response, global movement metrics, movement initiation, and feedback control. The selection of these groups is due, in part, to known differences in how parts of the sensorimotor circuit contribute to visually guided reaching. Control processes for posture and movement are somewhat distinct [61], and certain neurological disorders can affect one or the other [62]. Difficulties responding to a visual stimuli may not reflect a motor problem, such as in someone with hemianopsia. We found that from a cohort of subjects undergoing inpatient rehabilitation at our local hospital, approximately 80 percent of left-affected and 50 percent of right-affected subjects with stroke displayed differences from control subjects. Interestingly, approximately 40 percent of leftaffected subjects were flagged as performing differently from control subjects when they used the nonparetic right arms. Although many subjects may show differences across different groups of parameters, examples also exist in which unique patterns of deficits are found. For example, some subjects only displayed differences from controls in postural control or reaction time, but none related to movement itself. Thus, one can identify whether a subject has deficits in motor performance and, 
(a)
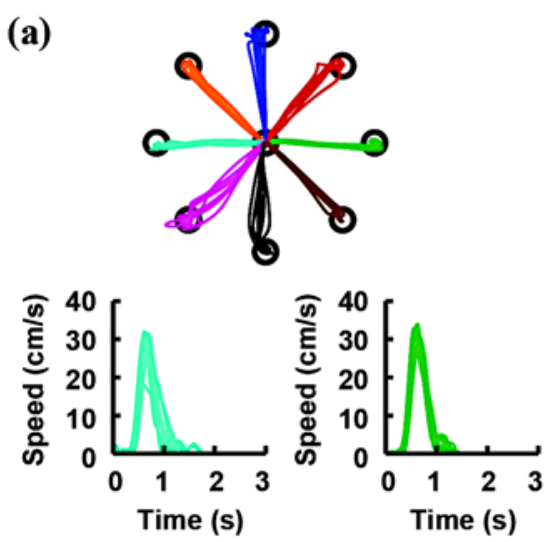

(b)
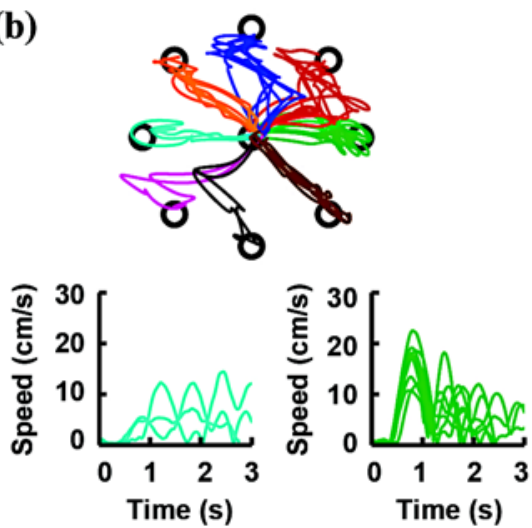

(c)
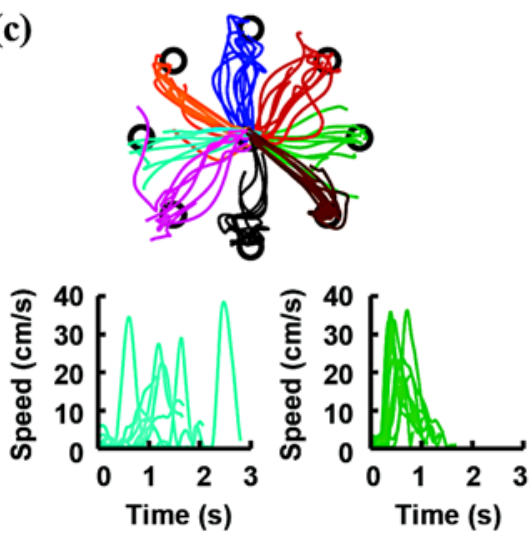
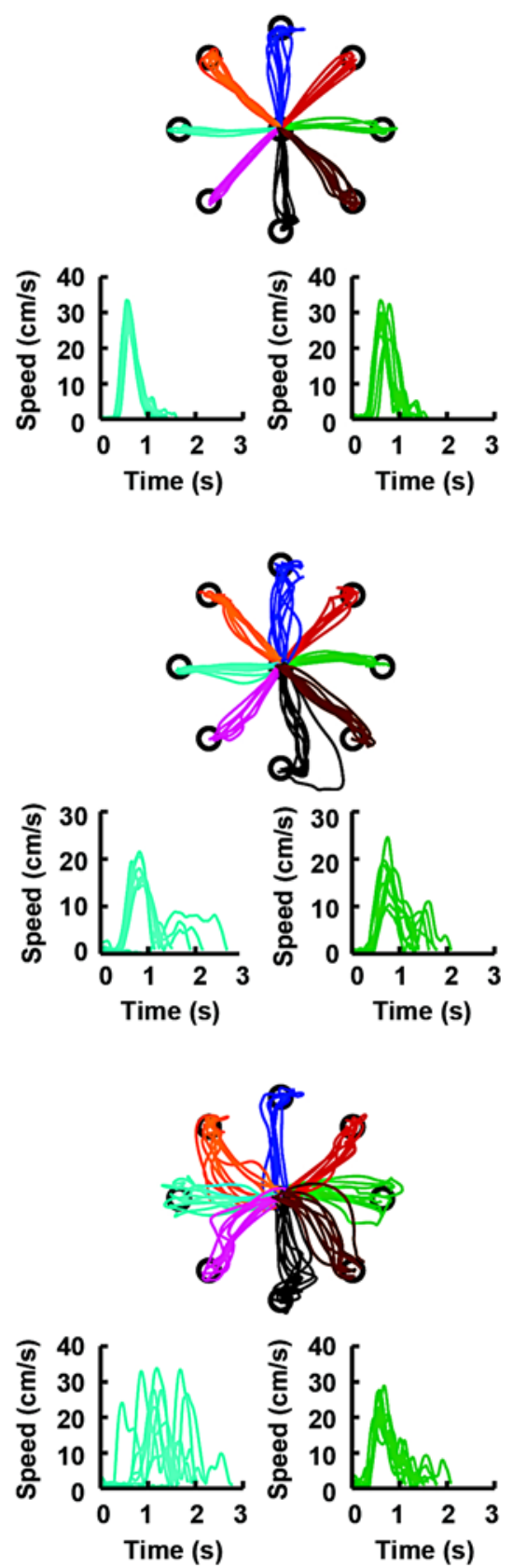

Figure 1.

Hand paths for visual-guided reaching movements from central target to one of eight peripheral targets for three subjects. Hand speed profiles for movements in left (cyan) and right directions (green) with zero time denoting onset time of peripheral visual target. (a) Control subject displaying relatively straight hand paths for all movement directions. Hand speed has single large peak and only a few small corrective movements. (b) Subject with right middle cerebral artery stroke. Hand paths display large initial direction errors and hand speed profiles display multiple large corrective movements for left-affected arm. Right arm shows some differences from control subject, notably systematic error for movements to lower target near subject. (c) Subject with right posterior cerebral artery stroke. Hand paths display large trial-to-trial variability. Hand speed plots display that reaction time was relatively short and consistent for movement to right, but were highly variable for movements to left using either left or right limbs. Data taken with institutional ethics approval from Coderre A, Zeid AA, Dukelow SP, Demmer MJ, Moore KD, Bretzke H, Herter TM, Glasgow JI, Norman KE, Bagg SD, Scott SH. Assessment of upper-limb sensorimotor function of subacute stroke patients using visually-guided reaching. Neurorehabil Neural Repair. 2010;24(6):528-41. 
importantly, quantify what features of this behavior are atypical. As a group, all the different measures of reaching performance create a unique fingerprint of impairments, which allows the possibility of designing rehabilitation programs that are targeted exactly at the patient's deficits. However, more research is clearly required to identify how different impairments affect disability and real-world use of the paretic limb [63].

Perhaps the greatest contribution of robotic technology to basic research has been the ability to apply novel mechanical loads to the limb to study motor learning [64-67]. Motor recovery following stroke can be generally viewed as a problem of motor learning, or in this case relearning, to use the paretic limb [68]. Therefore, an important potential of robots is to measure the capability of the motor system to learn after stroke. The work of Scheidt and Stoeckmann examined this issue by quantifying how neurologically intact and subjects with chronic stroke adapted to loads applied by a robot during reaching movements [69]. The magnitude of the load was randomly varied from trial to trial. For control subjects, motor patterns in a given trial correlate with the size of the error in the previous trial [70]. In other words, larger errors in the previous trial led to larger corrective movements in the next trial. They found that this trial-to-trial learning was reduced in subjects with stroke and covaried with the severity of the stroke. Further studies are needed to identify whether these measures of learning during the acute phase of stroke are related to the long process of recovery of motor abilities after a stroke.

These studies highlight only a few ways in which robotic technologies could be used to quantify motor impairments. In many ways these tasks remain relatively simple compared with the sophistication afforded by robots and virtual reality, such as the capability to simulate the properties of physical objects to explore object manipulation or permit tasks that require bimanual coordination.

\section{Robots for Upper-Limb Sensory Assessment}

Relatively simple approaches have been developed to quantify impairments in proprioceptive function for subjects with stroke [71-72], but they require manual repositioning of the limb. We have recently developed a robotbased system and quantified proprioceptive function of 45 patients at $\sim 1$ month poststroke and 65 age-matched nondisabled control subjects [73]. In this study, subjects' vision of the upper limbs was occluded, and the robot moved the paretic arm to different spatial locations in a random order. Subjects were required to mirror-match the geometry of the paretic limb with their nonparetic limb. The data from the matching arm were mirrored onto the robotic matching data. Subjects with stroke demonstrated a variety of deficits, including increased variability and spatial distortions of the entire target set. These spatial distortions were characterized by contraction, expansion, and/or systematic shifts of the two-dimensional target set (Figure 2). The study documented the reliability of the robotic technique for position sense assessment (intraclass correlation coefficient for variability, $r=0.81$ ), which was markedly better than that previously reported for standard clinical assessment tools [40,50]. Another recent study has used robotics to document proprioceptive deficits in the upper limbs of patients with stroke using an alternative approach to the one just described, which entailed the use of a two-alternative forced-choice paradigm to examine the perceptual detection threshold for hand perturbations [74].

Even a relatively simple task such as the limb-matching task in Dukelow et al. [73] requires several different processes or brain structures to be functional: (1) the left cerebral hemisphere must sense the position of the right limb moved by the robot, (2) this proprioceptive information computed must be transferred to right cerebral hemisphere, (3) the right cerebral hemisphere must plan and control the movement of the left limb, (4) the right hemisphere must sense the final position of the left limb, and (5) the two hemispheres must work together to compare the position of both limbs. Further, tests could be developed to separate these factors such as to move the limb to a spatial location temporarily with the robot and then the subject could be asked to replicate this position with the same limb [75].

\section{Robots for Cognitive Assessment}

Cognition relates to mental processes involved in awareness, attention, perception, language, memory, reasoning, and judgment. The multifaceted nature of cognition correspondingly requires a large battery of tests to quantify these processes. A full neuropsychological assessment is normally performed and requires many hours or even days to complete. These tests are labor intensive and based predominantly on subjective measures, questionnaires, and/or the use of pencil and paper. Simplified cognitive assessment tools have also been developed, including the Folstein Mini-Mental Status Exam [76] and the Montreal Cognitive Assessment [77], that 


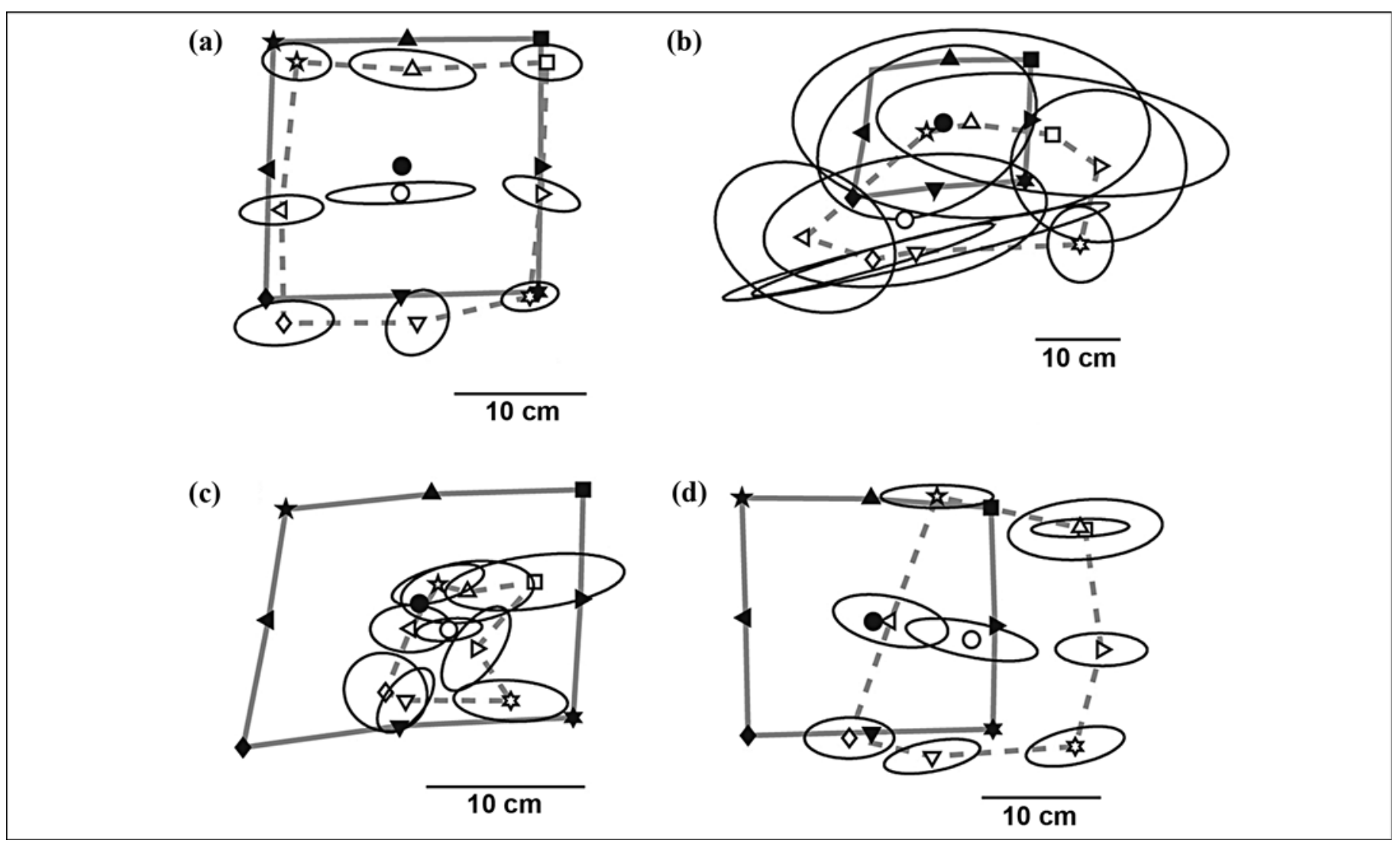

Figure 2.

Limb-matching capabilities of control subject and three subjects with stroke: (a) Matching performance for control subject. Robot moved left hand, and subjects were instructed to match mirror position with right arm. Filled icons denote locations where hand should have been positioned, and corresponding open icons denote mean location where subject placed their hand. Ellipses denote trial-to-trial variability for each location. (b) Subject with right middle cerebral artery (MCA) stroke. Robot moved left arm, and subject matched with right arm. Note large trial-to-trial variability. (c) Subject with left MCA stroke. Robot moved right arm, and subject matched with left arm. Note that stroke subject used greatly reduced region of workspace. (d) Subject with right posterior cerebral artery stroke. Robot moved left arm, and subject matched with right arm. Note shift in workspace. Data taken with institutional ethics approval from Dukelow SP, Herter TM, Moore KD, Demers MJ, Glasgow JI, Bagg SD, Norman KE, Scott SH. Quantitative assessment of limb position sense following stroke. Neurorehabil Neural Repair. 2010;24(2):178-87.

require relatively little time, although they are only screening tests to decide whether more thorough testing is required.

Some attempts have been made to automate certain aspects of these cognitive tasks. For example, CANTAB uses a touch-screen interface for performing over 20 tasks, ranging from simple movement tasks for quantifying reaction time to more complex tasks designed to assess spatial working memory (Cambridge Cognition; Cambridge, United Kingdom).

Robotic technology combined with virtual/augmented reality could also be used as an automated approach to quantify many aspects of cognitive function. In this situation, the upper limb is used as an output mea- sure of cognitive processes. Many traditional measures of cognition can be easily ported onto these systems, such as line-bisection tasks and trail making. Further, online measures of limb movement provide extra information on the pattern of motor behavior during the execution of these tasks. Importantly, robotic and virtual reality systems afford new opportunities to observe the ability of subjects to perform rapid decisional processes not examined in traditional pen-and-paper examinations. Finally, the use of the same technology to quantify sensory and motor functions of the upper limb can help differentiate whether difficulties to perform a cognitive task are due to lowerlevel sensory or motor impairments or actual problems in cognitive function. 


\section{Challenges and Future Directions in Robotic Assessment}

One might assume that the biggest hurdle for implementing robotic and other advanced technologies for neurological assessment is the substantial capital cost of the equipment. The "gold standards" for assessing neurological impairments are largely based on subjective observations, so these new assessment tools are assumed to be just as inexpensive. However, one should look at the broader impact of assessment to the healthcare system. Specifically, these "cheap” assessment tools drive many costly decisions on the patients' length of hospital stay and the amount and type of rehabilitation therapy they receive, as well as their long-term care strategies. Diagnostic tools that typically only provide information about body structure are routinely performed and quite expensive. For example, MRI is approximately 30 times more expensive to purchase and likely 5 times more expensive to operate than robotic systems. Yet these imaging technologies are clearly valuable to the healthcare system, widely available, and used regularly to make crucial decisions on patient care. Simply put, high-quality assessment tools with better diagnostic and prognostic precision will better healthcare and lower costs in the long run.

Perhaps the biggest challenge for using robots for assessment is that we still have only started to identify the ways that robots could be used to quantify brain dysfunction. Robots combined with virtual/augmented reality systems provide a general platform to study upperlimb sensory, motor, and cognitive function. They will potentially create an objective, quantitative approach to neurologically assess with continuous scores based on normative performance. The use of this technology for quantifying brain dysfunction is nascent, and thus considerable research is required to identify how they can be used for quantifying neurological impairment following stroke, how this information is related to ADLs, and how they can help guide effective patient-centered rehabilitation programs. Correspondingly, other neurological disorders will require this same systematic approach to identify how each behavioral task can also help with diagnosis, prognosis, and guidance of patient care.

As the library of robot-based tests increases, a new problem will arise with regard to the time required to assess a patient. This problem is common to all assessment tools. However, robots have a big advantage because sophisticated online analysis tools can be devel- oped to dramatically reduce the time required to assess a patient. Tasks can be organized into a tree or hierarchical structure with the assessment beginning with a few broad-based tasks. Atypical performance in one of these initial tasks will guide the selection of further testing to quantify in detail the underlying impairments. For example, increased reaction times during visually guided reaching could lead to further tasks that identify whether delayed responses reflect spatial neglect or a general problem of engaging the voluntary motor system. Further reductions in time with smart algorithms that decide to terminate a given task because performance was already identified as atypical. The result of these online analysis tools is that a comprehensive patient-centered approach to neurological assessment may require only a small subset of all possible tasks performed. The goal is to maximize the amount of information on brain function as quickly as possible.

While we believe that robots may potentially quantify many aspects of sensory, motor, and cognitive function, other technologies will also be necessary to provide a complete picture of brain function. Eye-tracking systems are needed to quantify oculomotor function, and when combined with robotic technologies, can quantify eyehand coordination skills. As well, motion-capture systems and force-plates provide important information on locomotion, balance, and other whole-body actions. Each technology has its strengths and weaknesses, but the combined use of various technologies provides a powerful radically new approach to neurological assessment. In effect, these facilities would function much like other diagnostic facilities within the healthcare system, such as imaging departments or laboratory medicine facilities. Clinicians can decide whether patients should receive a broad-based assessment or select a library of tasks specifically designed to address impairments associated with a certain disease or injury. Other possible roles for robotbased assessment technologies could be for triage, such as when a patient comes into the emergency room following a concussion and a clinician needs help to decide whether the patient requires more expensive testing such as an MRI to assess intracranial bleeding and whether he/ she should be admitted overnight or allowed to go home. Again, the final cost of each of these decisions can be substantial. 


\section{REHABILITATION OF STROKE}

\section{Traditional Approaches}

Traditional stroke rehabilitation strategies have focused largely on reducing motor impairments as a means of improving overall function [78]. In the research literature, this emphasis is reflected in the immense volume of publications focused on motor recovery and rehabilitation. Evidence is evolving for sensory [79], perceptual [80-82], and cognitive rehabilitation [83-84]. However, clinical implementation of rehabilitation for these issues is less pervasive. In stroke rehabilitation, therapy is often conducted by an individual or team of therapists, usually after a clinical assessment has been conducted. Given the inherent problems with clinical assessments discussed earlier, one can see how less than optimal assessment might translate into a less than optimal rehabilitation experience for the patient. Further, the type and dose of the rehabilitation treatment are largely controlled by the treating clinician and/or rehabilitation team. In our clinical experience, these factors vary significantly, which cannot always be explained by the patient's individual deficits. Treatment is typically concluded when the patient reaches a "plateau" in performance. This plateau is determined by the same problematic clinical tools already discussed. Some authors have suggested that this plateau may actually be the patients consolidating their poststroke practice experience rather than optimal biological recovery [85-87] and this, in itself, has important implications in the timing of how we deliver treatment after a stroke.

\section{Better Treatment Plan}

Like many areas in medicine, the delivery of stroke rehabilitation has much opportunity for improvement. Certain factors have been readily identified as affecting rehabilitation outcomes. The first is timing of stroke rehabilitation. Studies in animal models have demonstrated the importance of rehabilitation intervention within the first week following stroke to maximize neurological recovery [29]. In humans, earlier delivery of rehabilitation has been associated with better functional recovery [29-33,88-89]. The duration of therapy is a topic of some debate because traditional belief has been that the majority of neurologic recovery occurs within the first 4 months following stroke [90]. More recent studies with novel techniques such as constraint-induced movement therapy or robotics have demonstrated improve- ments in subjects several months beyond this [91-93]. In fact, a study is under way that will assess the capability of robotic rehabilitation to improve outcomes in stroke patients who are 56 months from their first stroke [94]. These more chronic studies reveal that subjects may continue to benefit from intensive rehabilitation much longer than traditionally thought.

Another factor identified as affecting stroke recovery is the intensity of rehabilitation. In general, studies in humans have demonstrated that greater intensity of rehabilitation leads to better outcomes [95-98].

Other authors have proposed the importance of the adaptability of the rehabilitation paradigm, such that the treatment evolves as the patient's performance improves [98]. This factor, however, requires constant reassessment, ideally with a highly sensitive tool, followed by adjustment of the treatment paradigm. Further optimal recovery should use a treatment paradigm tailored to the most effective learning style of the patient rather than employing a method constrained by the knowledge of the clinician or the programming of the device delivering therapy. Lastly, we suggest that considering the specific neurological deficits of the patient and targeting treatment at these deficits may be important. In the present rehabilitation environment, which focuses on motor recovery, other deficits receive minimal attention because we currently lack suitable treatment options.

\section{Rationale for Using Robots for Treatment}

Robots provide the capability to perform thousands of movement repetitions with precision. This factor has been shown to be important in motor retraining following stroke [99]. Further, these movements can be made with the robot either providing forces to the limb to assist or resisting movement. Such exacting control of movement is exceedingly difficult without a device. Additionally, the possibility exists to simultaneously monitor patient performance and modify the treatment paradigm as the patient progresses. Further, if normative assessment information was used, the robot could determine when subject performance fell within the normal range and accurately determine the conclusion of treatment in a given paradigm. Robotics also have the capability to simulate real-world situations through haptic interfaces and virtual reality [100-102].

Practically, the large volume of literature supporting the effectiveness of increased intensity and duration of rehabilitation [89,95-97] serves to highlight the importance 
of seeking potential alternatives to the traditional one-onone approach taken in stroke rehabilitation. Robots can deliver treatment with a therapy aide or technician supervising the operation of the device, thus allowing for a potential increase in the total dose of treatment received and optimizing use of the therapist's time. Further, most patients involved in research trials of rehabilitation with robots generally tolerate robotic therapy quite well and adverse events are exceptionally rare [103].

\section{Use of Robots for Rehabilitation}

A plethora of devices have been used to evaluate the effectiveness of robotics in improving motor recovery following stroke. Given the large number of devices that have been used in clinical trials, we created the Table in an attempt to summarize details about the devices and provide an example of a clinical study in which the robot has been used. The vast majority of robotic devices have focused on rehabilitating the proximal upper limb. Examples include devices such as the MIT-Manus robot (now marketed as the InMotion2, Interactive Motion Technologies, Inc; Boston, Massachusetts) [104] and the Mirror Image Motion Enabler (MIME) [105]. A few studies have used devices aimed at improving motor function in the wrist, including the Hand Wrist Assistive Rehabilitation Device [106] and the InMotion3 robot (Interactive Motion Technologies, Inc; Boston, Massachusetts) [107]. Some studies have combined functional electrical stimulation [108-109] or transcranial magnetic stimulation [110] with robotic therapy in attempts to improve outcomes. One study has examined trying to improve proprioception following stroke [111].

Each of the devices mentioned in the Table functions somewhat differently; some are end-point robots (e.g., InMotion2) while others are cable-based (e.g., NeReBot) or exoskeletal (e.g., ARMin). Many are unilateral (e.g., InMotion2, ARM Guide), while others are bilateral (e.g., MIME, Bi-Manu-Track). The MIME was designed to take advantage of "mirror therapy," in which movement in one arm could help to trigger movements in the other. The design of a robotic device effectively serves to physically constrain the movements of the upper limb. Devices such as the InMotion2 and the ARM Guide permit horizontal motion with the shoulder and elbow, while a device such as the Bi-Manu-Track allows for pronation and supination of the forearm. Other devices such as the NeReBot offer three-degrees-of-freedom movement that could potentially recreate more natural upper-limb move- ment. MIME provides six-degrees-of-freedom forearm motion on the hemiparetic side in three-dimensional space. However, no trial that we are aware of has directly compared two devices head-to-head.

The majority of clinical studies have explored the ability of a specific robotic device to improve motor impairments and disability following stroke. Some studies have been criticized for lacking appropriate control groups, because control groups were not present or did not receive an equivalent amount of therapy as the treatment group [104,112-113]. Other more recent studies have given control subjects an equivalent amount of traditional rehabilitation treatment [85] to control for the confound of differing intensity between control and robotic treatment groups. While we agree that an increased amount of therapy to robotic intervention groups represents a confound in terms of study design, it may actually represent a more real-world scenario then some previous critics have recognized. One can foresee robotic techniques being used in conjunction with and addition to standard rehabilitation techniques to optimize the delivery of stroke rehabilitation treatment.

Brewer et al. have previously reviewed the clinical studies conducted with each of the various robotic devices [114]. More recently, two systematic reviews have evaluated the evidence for robot-aided arm retraining following stroke $[99,103]$. These two reviews indicated that the use of robotics in rehabilitation was generally a safe treatment strategy, with rare adverse events and low subject drop-out rates. Further, stroke subjects demonstrated improvement in arm motor function and strength compared with control groups. Motor function in most of the studies reviewed was measured with the FM upper-limb stroke assessment [25] or the impairment inventory of the arm component of the Chedoke Assessment [24]. However, across the studies reviewed by either group, the ability to perform ADLs did not appear to improve. This finding is not at all surprising, given that most of the reviewed studies used the FIM [27] or the Barthel index [115] for measuring this. The authors of both systematic reviews point to the problems of using these common rehabilitation scales of overall function to measure the specific abilities of the upper limb-the FIM and Barthel Index heavily overrepresent the lower limb, and compensation with the less-paretic limb is allowed and not penalized. These facts could easily confound one's ability to determine whether an upper-limb treatment is effective in improving ADL performance. This 
problem further highlights the importance of having assessment tools that can accurately, reliably, and appropriately measure impairment and disability in the upper limb.

\section{Challenges and Future Directions in Robotic Therapy}

The implementation of any new treatment in medicine is not without challenges. One of the biggest obstacles faced can be translating research evidence into clinical practice. In this regard, many of the traditional treatment approaches in rehabilitation have been around for decades and the implementation of new techniques and technology may prove challenging.

One particular obstacle for robotic technology is the cost of the devices themselves. Lower-cost alternatives to the devices used in these studies are beginning to appear [116] and have been targeted at telerehabilitation in patient's homes. The higher cost of many robotic devices has generally led to their implementation as a researchbased tool in most centers. Kwakkel et al. have suggested the importance of a cost-effectiveness study on robotics in stroke rehabilitation [95]. Interestingly, a recent study found that the cost of robot-assisted therapy was relatively comparable to traditional approaches [117].

Following closely behind cost-related obstacles are those of access. Given that approximately 700,000 Americans, 920,000 Europeans, and 50,000 Canadians each year have a stroke, and a large number of these people require rehabilitation treatment, the issue of accessibility to novel treatments such as robotics is not a small one.

Further, some individuals have questioned the functional relevance of robotic retraining, given that most clinical trials have not established a clear benefit in the performance of ADLs. As discussed previously, this issue may be related as much to inherent problems with the assessment tools such as the FIM and Barthel Index as to the actual nature of the robotic rehabilitation. Also relevant, however, is that, with a few exceptions [106107], very few of the aforementioned studies attempt to rehabilitate the wrist and hand. Proficient performance of ADLs depends on both proximal and distal control of the upper limb.

Robotic rehabilitation strategies tend to use mass practice and explicit learning strategies [114]. Other authors have shown that this method may not be the most effective for motor relearning, because methods that involve contextual interference [118] and implicit learning [119120] may be better strategies poststroke. Although the opportunity exists to simultaneously assess and rehabilitate patients with robotic devices, this approach is not always employed. Most of the clinical trials conducted have relied on more traditional clinical assessments, each of which presents their own set of limitations. The development of valid and appropriate robotic assessment has lagged significantly behind the development of robotic rehabilitation tools and techniques. The assumption that our current assessment tools are "good enough" is being challenged as better, automated assessment methods evolve. Ultimately, better assessment methods may be required to truly demonstrate the advantages of applying new rehabilitation strategies, because the old methods are just too insensitive to change [79].

In efforts to move the field of stroke rehabilitation forward, we can see that some of the common clinical tools we use to assess neurological deficits are insufficient to guide novel treatments or appropriately measure the effects of these treatments. While more detailed and appropriate tests of function have been employed in some research studies (e.g., Wolf Motor Function test [34], Jebsen Taylor Hand function test [121]), these are not used routinely in clinical care, nor have they been used in most of the studies on robotic rehabilitation. Although these tests represent a potential improvement on assessments such as the FM [25], FIM [27], and Barthel Index [115], they still lack the ability to accurately measure vision, perception, and sensation accurately and succinctly. The evolution of robotic assessment offers the capability to quantify these changes with great accuracy and reliability, but much work needs to be done to establish appropriate and meaningful assessment tools. This likely involves quantitating both neurological impairments and the problems these impairments create when patients are trying to accomplish ADLs.

Rehabilitation of stroke deficits has been the target of researchers for some time now, with the first studies being published nearly 13 years ago [113]. Much like traditional rehabilitation approaches, researchers have focused extensively on mass practice and explicit motor relearning. While this method has certainly demonstrated some success, room for improvement exists. First, one might consider integrated automated assessment and treatment. Second, alternative learning strategies might further enhance recovery. Third, rehabilitation of deficits beyond those in the motor system need further exploration [79]. Fourth, rehabilitation on the entire upper limb is 
critical, given the importance of the hand in performance of ADLs.

\section{CONCLUSIONS}

This review highlights the present challenges facing clinical assessment of upper-limb impairments related to stroke and associated therapeutic interventions. We suggest that robots could create a new approach to clinical assessment and rehabilitation building from present knowledge on how neural circuits in the brain generate the various sensory, motor, and cognitive function. Although the capital costs of these technologies are much more than existing approaches, they may potentially provide a much more cost-effective approach to patient care, offering a broader, more complete assessment of neurological impairments and the capability to support treatment that may be better suited for the specific needs of each patient.

\section{ACKNOWLEDGMENTS}

\section{Author Contributions: \\ Drafting of manuscript: S. H. Scott, S. P. Dukelow. Critical revision of manuscript for important intellectual content: S. H. Scott, S. P. Dukelow. \\ Financial Disclosures: Stephen H. Scott is cofounder and Chief Scientific Officer of BKIN Technologies, which commercializes robotic technologies for clinical and basic research.}

Funding/Support: This material was based on work supported by a grant (MOP 81366) from the Canadian Institutes of Health Research, an Ontario Research Foundation-Research Excellence Grant, and funds from Department of Clinical Neurosciences at the University of Calgary. Sean P. Dukelow was supported by a salary award from the Heart and Stroke Foundation of Alberta, Northwest Territories and Nunavut.

Additional Contributions: We give special thanks to Dr. Troy Herter for preparing the figures for this article.

\section{REFERENCES}

1. Paci M. Physiotherapy based on the Bobath concept for adults with post-stroke hemiplegia: A review of effectiveness studies. J Rehabil Med. 2003;35(1):2-7.

[PMID: 12610841] DOI:10.1080/16501970306106

2. Pollock A, Baer G, Langhorne P, Pomeroy V. Physiotherapy treatment approaches for the recovery of postural control and lower limb function following stroke: A systematic review. Clin Rehabil. 2007;21(5):395-410.

[PMID: 17613560]

DOI:10.1177/0269215507073438

3. Kollen BJ, Lennon S, Lyons B, Wheatley-Smith L, Scheper M, Buurke JH, Halfens J, Geurts AC, Kwakkel G. The effectiveness of the Bobath concept in stroke rehabilitation: What is the evidence? Stroke. 2009;40(4):e89-97. [PMID: 19182079] DOI:10.1161/STROKEAHA.108.533828

4. Kandel ES, Schwartz JH, Jessell TM. Principles of neural science. 4th ed. New York (NY): McGraw-Hill, Health Professions Division; 2000.

5. Shadmehr R, Wise SP. The computational neurobiology of reaching and pointing: A foundation for motor learning. Combridge (MA): MIT Press; 2005.

6. Stein BE, Meredith MA. The merging of the senses. Cambridge (MA): MIT Press; 1993.

7. Yuille A, Kersten D. Vision as Bayesian inference: Analysis by synthesis? Trends Cogn Sci. 2006;10(7):301-8.

[PMID: 16784882] DOI:10.1016/j.tics.2006.05.002

8. Wolpert DM, Ghahramani Z, Flanagan JR. Perspectives and problems in motor learning. Trends Cogn Sci. 2001; 5(11):487-94. [PMID: 11684481]

DOI:10.1016/S1364-6613(00)01773-3

9. Kalaska JF, Scott SH, Cisek P, Sergio LE. Cortical control of reaching movements. Curr Opin Neurobiol. 1997;7(6): 849-59. [PMID: 9464979] DOI:10.1016/S0959-4388(97)80146-8

10. Scott SH, Kalaska JF. Reaching movements with similar hand paths but different arm orientations. I. Activity of individual cells in motor cortex. J Neurophysiol. 1997; 77(2):826-52. [PMID: 9065853]

11. Kolb B, Whishaw IQ. Brain plasticity and behavior. Annu Rev Psychol. 1998;49:43-64. [PMID: 9496621] DOI:10.1146/annurev.psych.49.1.43

12. Nudo RJ, Plautz EJ, Frost SB. Role of adaptive plasticity in recovery of function after damage to motor cortex. Muscle Nerve. 2001;24(8):1000-1019. [PMID: 11439375] DOI:10.1002/mus.1104

13. Buonomano DV, Merzenich MM. Cortical plasticity: From synapses to maps. Annu Rev Neurosci. 1998;21: 149-86. [PMID: 9530495]

DOI:10.1146/annurev.neuro.21.1.149

14. Bapi RS, Miyapuram KP, Graydon FX, Doya K. fMRI investigation of cortical and subcortical networks in the learning of abstract and effector-specific representations of motor sequences. Neuroimage. 2006;32(2):714-27.

[PMID: 16798015]

DOI:10.1016/j.neuroimage.2006.04.205 
15. Hesse S, Werner C. Poststroke motor dysfunction and spasticity: Novel pharmacological and physical treatment strategies. CNS Drugs. 2003;17(15):1093-1107.

[PMID: 14661987]

DOI:10.2165/00023210-200317150-00004

16. Klit H, Finnerup NB, Jensen TS. Central post-stroke pain: Clinical characteristics, pathophysiology, and management. Lancet Neurol. 2009;8(9):857-68. [PMID: 19679277$]$ DOI:10.1016/S1474-4422(09)70176-0

17. Körding KP, Wolpert DM. Bayesian decision theory in sensorimotor control. Trends Cogn Sci. 2006;10(7):319-26. [PMID: 16807063]

DOI:10.1016/j.tics.2006.05.003

18. Glimcher PW, Camerer C, Poldrack RA, Fehr E. Neuroeconomics: Decision making and the brain. New York (NY): Academic Press; 2009.

19. Todorov E. Optimality principles in sensorimotor control. Nat Neurosci. 2004;7(9):907-15. [PMID: 15332089] DOI:10.1038/nn1309

20. Scott SH. Optimal feedback control and the neural basis of volitional motor control. Nat Rev Neurosci. 2004;5(7): 532-46. [PMID: 15208695]

DOI:10.1038/nrn1427

21. Scott SH, Norman KE. Computational approaches to motor control and their potential role for interpreting motor dysfunction. Curr Opin Neurol. 2003;16(6):693-98. [PMID: 14624078] DOI:10.1097/00019052-200312000-00008

22. Medical Research Council. Aids to the investigation of peripheral nerve injuries. 2d ed. War Memorandum No. 7. London: Her Majesty’s Stationery Office; 1943. p. 1-2.

23. MacAvoy MC, Green DP. Critical reappraisal of Medical Research Council muscle testing for elbow flexion. J Hand Surg Am. 2007;32(2):149-53. [PMID: 17275586$]$ DOI:10.1016/j.jhsa.2006.10.020

24. Gowland C, Stratford P, Ward M, Moreland J, Torresin W, Van Hullenaar S, Sanford J, Barreca S, Vanspall B, Plews N. Measuring physical impairment and disability with the Chedoke-McMaster Stroke Assessment. Stroke. 1993;24(1): 58-63. [PMID: 8418551]

25. Fugl-Meyer AR, Jääskö L, Leyman I, Olsson S, Steglind S. The post-stroke hemiplegic patient. 1. A method for evaluation of physical performance. Scand J Rehabil Med. 1975;7(1):13-31. [PMID: 1135616]

26. Barreca S, Gowland CK, Stratford P, Huijbregts M, Griffiths J, Torresin W, Dunkley M, Miller P, Masters. Development of the Chedoke Arm and Hand Activity Inventory: Theoretical constructs, item generation, and selection. Top Stroke Rehabil. 2004;11(4):31-42.

[PMID: 15592988]

DOI:10.1310/JU8P-UVK6-68VW-CF3W
27. Keith RA, Granger CV, Hamilton BB, Sherwin FS. The functional independence measure: A new tool for rehabilitation. Adv Clin Rehabil. 1987;1:6-18. [PMID: 3503663]

28. Wilson B, Cockburn J, Halligan P. Development of a behavioral test of visuospatial neglect. Arch Phys Med Rehabil. 1987;68(2):98-102. [PMID: 3813864]

29. Biernaskie J, Chernenko G, Corbett D. Efficacy of rehabilitative experience declines with time after focal ischemic brain injury. J Neurosci. 2004;24(5):1245-54.

[PMID: 14762143]

DOI:10.1523/JNEUROSCI.3834-03.2004

30. Feigenson JS, McCarthy ML, Meese PD, Feigenson WD, Greenberg SD, Rubin E, McDowell FH. Stroke rehabilitation I. Factors predicting outcome and length of stay-An overview. N Y State J Med. 1977;77(9):1426-30.

[PMID: 267835]

31. Hayes SH, Carroll SR. Early intervention care in the acute stroke patient. Arch Phys Med Rehabil. 1986;67(5):319-21. [PMID: 3707317]

32. Cifu DX, Stewart DG. Factors affecting functional outcome after stroke: A critical review of rehabilitation interventions. Arch Phys Med Rehabil. 1999;80(5 Suppl 1): S35-39. [PMID: 10326901] DOI:10.1016/S0003-9993(99)90101-6

33. Ottenbacher KJ, Jannell S. The results of clinical trials in stroke rehabilitation research. Arch Neurol. 1993;50(1): 37-44. [PMID: 8418798]

34. Wolf SL, Catlin PA, Ellis M, Archer AL, Morgan B, Piacentino A. Assessing Wolf motor function test as outcome measure for research in patients after stroke. Stroke. 2001; 32(7):1635-39. [PMID: 11441212]

35. Campbell WW, DeJong RN, Haerer AF. DeJong's the neurologic examination: Incorporating the fundamentals of neuro anatomy and neurophysiology. 5th ed. New York (NY): J.B. Lippincott \& Co.; 1997.

36. Lephart SM, Riemann BL, Fu FH. Introduction to the sensorimotor system. In: Lephart SM, Fu FH, editors. Proprioception and neuromuscular control in joint stability. Champaign (IL): Human Kinetics; 2000. p. xvii-xxiv.

37. Riemann BL, Lephart SM. The sensorimotor system, part II: The role of proprioception in motor control and functional joint stability. J Athl Train. 2002;37(1):80-84. [PMID: 16558671$]$

38. Sherrington CS. On the proprio-ceptive system, especially in its reflex aspect. Brain. 1907;29(4):467-82.

DOI:10.1093/brain/29.4.467

39. Bickley LS, Szilagyi PG. Bates’ guide to physical examination and history taking. 9th ed. Philadelphia (PA): Lippincott Williams \& Wilkins; 2007.

40. Lincoln NB, Crow JL, Jackson JM, Waters GR, Adams SA, Hodgson P. The unreliability of sensory assessments. 
Clin Rehabil. 1991;5(4):273-82.

DOI:10.1177/026921559100500403

41. Hirayama K, Fukutake T, Kawamura M. 'Thumb localizing test' for detecting a lesion in the posterior columnmedial lemniscal system. J Neurol Sci. 1999;167(1):45-49. [PMID: 10500261] DOI:10.1016/S0022-510X(99)00136-7

42. Reding MJ. A model stroke classification scheme and its use in outcome research. Stroke. 1990;21(9 Suppl):II35-37. [PMID: 2399548]

43. Shah SK. Deficits affected the function of the paralyzed arm following hemiplegia. Aust Occup Ther J. 1978;25(2): 12-19. DOI:10.1111/j.1440-1630.1978.tb00656.x

44. De Weerdt W, Lincoln NB, Harrison MA. Prediction of arm and hand function recovery in stroke patients. Int $\mathrm{J}$ Rehabil Res. 1987;10(4 Suppl 5):110-12.

[PMID: 3503832]

45. Kuffosky A, Wadell, I, Nilsson, BY. The relationship between sensory impairment and motor recovery in patients with hemiplegia. Scand J Rehabil Med. 1982; 14(1):27-32. [PMID: 7073817]

46. La Joie WJ, Reddy NM, Melvin JL. Somatosensory evoked potentials: Their predictive value in right hemiplegia. Arch Phys Med Rehabil. 1982;63(5):223-26. [PMID: 7073461]

47. Pavot AP, Ignacio DR, Kuntavanish A, Lightfoote WE 2nd. The prognostic value of somatosensory evoked potentials in cerebrovascular accidents. Electromyogr Clin Neurophysiol. 1986;26(5-6):333-40.

[PMID: 3780520$]$

48. Wade DT, Langton-Hewer R, Wood VA, Skilbeck CE, Ismail HM. The hemiplegic arm after stroke: Measurement and recovery. J Neurol Neurosurg Psychiatry. 1983; 46(6):521-24. [PMID: 6875585] DOI:10.1136/jnnp.46.6.521

49. Lin JH, Hsueh IP, Sheu CF, Hsieh CL. Psychometric properties of the sensory scale of the Fugl-Meyer Assessment in stroke patients. Clin Rehabil. 2004;18(4):391-97. [PMID: 15180122] DOI:10.1191/0269215504cr737oa

50. Garraway WM, Akhtar AJ, Gore SM, Prescott RJ, Smith RG. Observer variation in the clinical assessment of stroke. Age Ageing. 1976;5(4):233-40. [PMID: 1008010] DOI:10.1093/ageing/5.4.233

51. Carey LM. Somatosensory loss after stroke. Crit Rev Phys Rehabil Med. 1995;7:51-91.

52. Marsden CD, Merton PA, Morton HB, Adam J. The effect of lesions of the sensorimotor cortex and the capsular pathways on servo responses from the human long thumb flexor. Brain. 1977;100(3):503-26. [PMID: 589429] DOI:10.1093/brain/100.3.503

53. Coderre A, Zeid AA, Dukelow SP, Demmer MJ, Moore KD, Bretzke H, Herter TM, Glasgow JI, Norman KE,
Bagg SD, Scott SH. Assessment of upper-limb sensorimotor function of subacute stroke patients using visuallyguided reaching. Neurorehabil Neural Repair. 2010;24(6): 528-41.[PMID: 20233965$]$ DOI:10.1177/1545968309356091

54. Scott SH. Apparatus for measuring and perturbing shoulder and elbow joint positions and torques during reaching. J Neurosci Methods. 1999;89(2):119-27.

[PMID: 10491942] DOI:10.1016/S0165-0270(99)00053-9

55. Dick JP, Rothwell JC, Day BL, Wise RJ, Benecke R, Marsden CD. Modulation of the long-latency reflex to stretch by the supplementary motor area in humans. Neurosci Lett. 1987;75(3):349-54. [PMID: 3587739$]$ DOI:10.1016/0304-3940(87)90548-9

56. Trumbower RD, Ravichandran VJ, Krutky MA, Perreault EJ. Altered multijoint reflex coordination is indicative of motor impairment level following stroke. Conf Proc IEEE Eng Med Biol Soc. 2008;2008:3558-61. [PMID: 19163477]

57. Ellis MD, Sukal T, DeMott T, Dewald JP. Augmenting clinical evaluation of hemiparetic arm movement with a laboratory-based quantitative measurement of kinematics as a function of limb loading. Neurorehabil Neural Repair. 2008;22(4):321-29. [PMID: 18326888]

DOI:10.1177/1545968307313509

58. Yarosh CA, Hoffman DS, Strick PL. Deficits in movements of the wrist ipsilateral to a stroke in hemiparetic subjects. J Neurophysiol. 2004;92(6):3276-85.

[PMID: 15295013] DOI:10.1152/jn.00549.2004

59. Bosecker C, Dipietro L, Volpe B, Krebs HI. Kinematic robot-based evaluation scales and clinical counterparts to measure upper limb motor performance in patients with chronic stroke. Neurorehabil Neural Repair. 2010;24(1): 62-69. [PMID: 19684304]

DOI:10.1177/1545968309343214

60. Abstracts From the 1st Canadian Stroke Congress. In: Dukelow SP, Herter TM, Scott SH. Independence of limb position sense and motor impairments following stroke [abstract]. Stroke. 2010;41:e473-e510. DOI:10.1161/STR.0b013e3181eb3152

61. Kurtzer I, Herter TM, Scott SH. Random change in cortical load representation suggests distinct control of posture and movement. Nat Neurosci. 2005;8(4):498-504. [PMID: 15768037]

62. Deuschl G, Bain P, Brin M. Consensus statement of the Movement Disorder Society on Tremor. Ad Hoc Scientific Committee. Mov Disord. 1998;13 Suppl 3:2-23.

[PMID: 9827589]

DOI:10.1002/mds.870131303

63. Lum PS, Mulroy S, Amdur RL, Reqeujo P, Prilutsky BI, Dromerick AW. Gains in upper extremity function after 
stroke via recovery or compensation: Potential differential effects on amount of real-world limb use. Top Stroke Rehabil. 2009;16(4):237-53. [PMID: 19740730] DOI:10.1310/tsr1604-237

64. Shadmehr R, Mussa-Ivaldi FA. Adaptive representation of dynamics during learning of a motor task. J Neurosci. 1994;14(5 Pt 2):3208-24. [PMID: 8182467]

65. Goodbody SJ, Wolpert DM. Temporal and amplitude generalization in motor learning. J Neurophysiol. 1998;79(4): 1825-38. [PMID: 9535951]

66. Singh K, Scott SH. A motor learning strategy reflects neural circuitry for limb control. Nat Neurosci. 2003;6(4): 399-403. [PMID: 12627165$]$ DOI:10.1038/nn1026

67. Doya K. What are the computations of the cerebellum, the basal ganglia and the cerebral cortex? Neural Netw. 1999; 12(7-8):961-74. [PMID: 12662639] DOI:10.1016/S0893-6080(99)00046-5

68. Huang VS, Krakauer JW. Robotic neurorehabilitation: A computational motor learning perspective. J Neuroeng Rehabil. 2009;6:5. [PMID: 19243614] DOI:10.1186/1743-0003-6-5

69. Scheidt RA, Stoeckmann T. Reach adaptation and final position control amid environmental uncertainty after stroke. J Neurophysiol. 2007;97(4):2824-36.

[PMID: 17267755]

DOI:10.1152/jn.00870.2006

70. Scheidt RA, Dingwell JB, Mussa-Ivaldi FA. Learning to move amid uncertainty. J Neurophysiol. 2001;86(2):971-85. [PMID: 11495965]

71. Carey LM, Oke LE, Matyas TA. Impaired limb position sense after stroke: A quantitative test for clinical use. Arch Phys Med Rehabil. 1996;77(12):1271-78.

[PMID: 8976311] DOI:10.1016/S0003-9993(96)90192-6

72. Leibowitz N, Levy N, Weingarten S, Grinberg Y, Karniel A, Sacher Y, Serfaty C, Soroker N. Automated measurement of proprioception following stroke. Disabil Rehabil. 2008;30(24):1829-36. [PMID: 19037777] DOI:10.1080/09638280701640145

73. Dukelow SP, Herter TM, Moore KD, Demers MJ, Glasgow JI, Bagg SD, Norman KE, Scott SH. Quantitative assessment of limb position sense following stroke. Neurorehabil Neural Repair. 2010;24(2):178-87.

[PMID: 19794134]

DOI:10.1177/1545968309345267

74. Scheidt RA SLS, Ghez C, Wieser JA. Robotic evaluation of arm proprioception following stroke. Society for Neuroscience; Chicago, IL. 2009. Available from: http:// www.sfn.org/am2009/index.aspx?pagename=abstract main/

75. Fuentes CT, Bastian AJ. Where is your arm? Variations in proprioception across space and tasks. J Neurophysiol.
2010;103(1):164-71. [PMID: 19864441]

DOI:10.1152/jn.00494.2009

76. Folstein MF, Folstein SE, McHugh PR. "Mini-mental state.” A practical method for grading the cognitive state of patients for the clinician. J Psychiatr Res. 1975;12(3): 189-98. [PMID: 1202204$]$ DOI:10.1016/0022-3956(75)90026-6

77. Nasreddine ZS, Phillips NA, Bédirian V, Charbonneau S, Whitehead V, Collin I, Cummings JL, Chertkow H. The Montreal Cognitive Assessment, MoCA: A brief screening tool for mild cognitive impairment. J Am Geriatr Soc. 2005;53(4):695-99. [PMID: 15817019] DOI:10.1111/j.1532-5415.2005.53221.X

78. Bobath B. Adult hemiplegia: Evaluation and treatment. London (UK): Heinemann; 1971.

79. Schabrun SM, Hillier S. Evidence for the retraining of sensation after stroke: A systematic review. Clin Rehabil. 2009;23(1):27-39. [PMID: 19114435] DOI:10.1177/0269215508098897

80. Weinberg J, Diller L, Gordon WA, Gerstman LJ, Lieberman A, Lakin P, Hodges G, Ezrachi O. Visual scanning training effect on reading-related tasks in acquired right brain damage. Arch Phys Med Rehabil. 1977;58(11):479-86. [PMID: 931586]

81. Weinberg J, Diller L, Gordon WA, Gerstman LJ, Lieberman A, Lakin P, Hodges G, Ezrachi O. Training sensory awareness and spatial organization in people with right brain damage. Arch Phys Med Rehabil. 1979;60(11):491-96. [PMID: 508074]

82. Gordon WA, Hibbard MR, Egelko S, Diller L, Shaver MS, Lieberman A, Ragnarsson K. Perceptual remediation in patients with right brain damage: A comprehensive program. Arch Phys Med Rehabil. 1985;66(6):353-59. [PMID: 4004531]

83. Cicerone KD, Dahlberg C, Kalmar K, Langenbahn DM, Malec JF, Bergquist TF, Felicetti T, Giacino JT, Harley JP, Harrington DE, Herzog J, Kneipp S, Laatsch L, Morse PA. Evidence-based cognitive rehabilitation: Recommendations for clinical practice. Arch Phys Med Rehabil. 2000;81(12):1596-1615. [PMID: 11128897] DOI:10.1053/apmr.2000.19240

84. Cicerone KD, Dahlberg C, Malec JF, Langenbahn DM, Felicetti T, Kneipp S, Ellmo W, Kalmar K, Giacino JT, Harley JP, Laatsch L, Morse PA, Catanese J. Evidencebased cognitive rehabilitation: Updated review of the literature from 1998 through 2002. Arch Phys Med Rehabil. 2005;86(8):1681-92. [PMID: 16084827]

DOI:10.1016/j.apmr.2005.03.024

85. Volpe BT, Lynch D, Rykman-Berland A, Ferraro M, Galgano M, Hogan N, Krebs HI. Intensive sensorimotor arm training mediated by therapist or robot improves hemiparesis in patients with chronic stroke. Neurorehabil Neural 
Repair. 2008;22(3):305-10. [PMID: 18184932]

DOI:10.1177/1545968307311102

86. Hogan N, Krebs HI, Rohrer B, Palazzolo JJ, Dipietro L, Fasoli SE, Stein J, Hughes R, Frontera WR, Lynch D, Volpe BT. Motions or muscles? Some behavioral factors underlying robotic assistance of motor recovery. J Rehabil Res Dev. 2006;43(5):605-18. [PMID: 17123202] DOI:10.1682/JRRD.2005.06.0103

87. Page SJ, Gater DR, Bach YR. Reconsidering the motor recovery plateau in stroke rehabilitation. Arch Phys Med Rehabil. 2004;85(8):1377-81. [PMID: 15295770] DOI:10.1016/j.apmr.2003.12.031

88. Huang HC, Chung KC, Lai DC, Sung SF. The impact of timing and dose of rehabilitation delivery on functional recovery of stroke patients. J Chin Med Assoc. 2009;72(5): 257-64. [PMID: 19467949] DOI:10.1016/S1726-4901(09)70066-8

89. Teasell R, Bitensky J, Salter K, Bayona NA. The role of timing and intensity of rehabilitation therapies. Top Stroke Rehabil. 2005;12(3):46-57. [PMID: 16110427] DOI:10.1310/ETDP-6DR4-D617-VMVF

90. Jørgensen HS, Nakayama H, Raaschou HO, Vive-Larsen J, Støier M, Olsen TS. Outcome and time course of recovery in stroke. Part II: Time course of recovery. The Copenhagen Stroke Study. Arch Phys Med Rehabil. 1995; 76(5):406-12. [PMID: 7741609]

DOI:10.1016/S0003-9993(95)80568-0

91. Wolf SL, Winstein CJ, Miller JP, Taub E, Uswatte G, Morris D, Giuliani C, Light KE, Nichols-Larsen D; EXCITE Investigators. Effect of constraint-induced movement therapy on upper extremity function 3 to 9 months after stroke: The EXCITE randomized clinical trial. JAMA. 2006;296(17):2095-2104. [PMID: 17077374]

92. Posteraro F, Mazzoleni S, Aliboni S, Cesqui B, Battaglia A, Dario P, Micera S. Robot-mediated therapy for paretic upper limb of chronic patients following neurological injury. J Rehabil Med. 2009;41(12):976-80.

[PMID: 19841827]

DOI:10.2340/16501977-0403

93. Bovolenta F, Goldoni M, Clerici P, Agosti M, Franceschini M. Robot therapy for functional recovery of the upper limbs: A pilot study on patients after stroke. J Rehabil Med. 2009;41(12):971-75. [PMID: 19841826] DOI:10.2340/16501977-0402

94. Lo AC, Guarino P, Krebs HI, Volpe BT, Bever CT, Duncan PW, Ringer RJ, Wagner TH, Richards LG, Bravata DM, Haselkorn JK, Wittenberg GF, Federman DG, Corn $\mathrm{BH}$, Maffucci AD, Peduzzi P. Multicenter randomized trial of robot-assisted rehabilitation for chronic stroke: Methods and entry characteristics for VA ROBOTICS. Neurorehabil Neural Repair. 2009;23(8):775-83.

[PMID: 19541917] DOI:10.1177/1545968309338195
95. Kwakkel G, Wagenaar RC, Koelman TW, Lankhorst GJ, Koetsier JC. Effects of intensity of rehabilitation after stroke. A research synthesis. Stroke. 1997;28(8):1550-56. [PMID: 9259747]

96. Kwakkel G, Wagenaar RC, Twisk JW, Lankhorst GJ, Koetsier JC. Intensity of leg and arm training after primary middle-cerebral-artery stroke: A randomised trial. Lancet. 1999;354(9174):191-96. [PMID: 10421300] DOI:10.1016/S0140-6736(98)09477-X

97. Langhorne P, Wagenaar R, Partridge C. Physiotherapy after stroke: More is better? Physiother Res Int. 1996;1(2): 75-88. [PMID: 9238725]

98. Teasell R. Evidence based review of stroke rehabilitation [Internet]. London (Canada): EBRSR; 2009. Available from: www.ebrsr.com

99. Kwakkel G, Kollen BJ, Krebs HI. Effects of robot-assisted therapy on upper limb recovery after stroke: A systematic review. Neurorehabil Neural Repair. 2008;22(2):111-21. [PMID: 17876068] DOI:10.1177/1545968307305457

100. Adamovich SV, Fluet GG, Merians AS, Mathai A, Qiu Q. Incorporating haptic effects into three-dimensional virtual environments to train the hemiparetic upper extremity. IEEE Trans Neural Syst Rehabil Eng. 2009;17(5):512-20. [PMID: 19666345] DOI:10.1109/TNSRE.2009.2028830

101. Oblak J, Cikajlo I, Matjaci Z. Universal haptic drive: A robot for arm and wrist rehabilitation. IEEE Trans Neural Syst Rehabil Eng. 2010;18(3):293-302. [PMID: 1984386] DOI:10.1109/TNSRE.2009.2034162

102. Ueki S, Nishimoto Y, Abe M, Kawasaki H, Ito S, Ishigure Y, Mizumoto J, Ojika T. Development of virtual reality exercise of hand motion assist robot for rehabilitation therapy by patient self-motion control. Conf Proc IEEE Eng Med Biol Soc. 2008;2008:4282-85. [PMID: 19163659]

103. Mehrholz J, Platz T, Kugler J, Pohl M. Electromechanical and robot-assisted arm training for improving arm function and activities of daily living after stroke. Stroke. 2009. [Epub ahead of print]. [PMID: 19286592$]$

104. Krebs HI, Hogan N, Aisen ML, Volpe BT. Robot-aided neurorehabilitation. IEEE Trans Rehabil Eng. 1998;6(1): 75-87. [PMID: 9535526]

DOI:10.1109/86.662623

105. Burgar CG, Lum PS, Shor PC, Machiel Van der Loos HF. Development of robots for rehabilitation therapy: The Palo Alto VA/Stanford experience. J Rehabil Res Dev. 2000;37(6):663-73. [PMID: 11321002]

106. Takahashi CD, Der-Yeghiaian L, Le V, Motiwala RR, Cramer SC. Robot-based hand motor therapy after stroke. Brain. 2008;131(Pt 2):425-37. [PMID: 18156154] DOI:10.1093/brain/awm311 
107. Krebs HI, Volpe BT, Williams D, Celestino J, Charles SK, Lynch D, Hogan N. Robot-aided neurorehabilitation: A robot for wrist rehabilitation. IEEE Trans Neural Syst Rehabil Eng. 2007;15(3):327-35. [PMID: 17894265] DOI:10.1109/TNSRE.2007.903899

108. Daly JJ, Hogan N, Perepezko EM, Krebs HI, Rogers JM, Goyal KS, Dohring ME, Fredrickson E, Nethery J, Ruff RL. Response to upper-limb robotics and functional neuromuscular stimulation following stroke. J Rehabil Res Dev. 2005;42(6):723-36. [PMID: 16680610] DOI:10.1682/JRRD.2005.02.0048

109. Hughes AM, Freeman CT, Burridge JH, Chappell PH, Lewin PL, Rogers E. Feasibility of iterative learning control mediated by functional electrical stimulation for reaching after stroke. Neurorehabil Neural Repair. 2009; 23(6):559-68. [PMID: 19190087] DOI: $10.1177 / 1545968308328718$

110. Edwards DJ, Krebs HI, Rykman A, Zipse J, Thickbroom GW, Mastaglia FL, Pascual-Leone A, Volpe. Raised corticomotor excitability of M1 forearm area following anodal tDCS is sustained during robotic wrist therapy in chronic stroke. Restor Neurol Neurosci. 2009;27(3):199-207. [PMID: 19531875]

111. Casadio M, Morasso P, Sanguineti V, Giannoni P. Minimally assistive robot training for proprioception enhancement. Exp Brain Res. 2009;194(2):219-31. [PMID: 19139867] DOI:10.1007/s00221-008-1680-6

112. Aisen ML, Krebs HI, Hogan N, McDowell F, Volpe BT. The effect of robot-assisted therapy and rehabilitative training on motor recovery following stroke. Arch Neurol. 1997;54(4):443-46. [PMID: 9109746]

113. Masiero S, Celia A, Rosati G, Armani M. Robotic-assisted rehabilitation of the upper limb after acute stroke. Arch Phys Med Rehabil. 2007;88(2):142-49.

[PMID: 17270510]

DOI:10.1016/j.apmr.2006.10.032

114. Brewer BR, McDowell SK, Worthen-Chaudhari LC. Poststroke upper extremity rehabilitation: A review of robotic systems and clinical results. Top Stroke Rehabil. 2007; 14(6):22-44. [PMID: 18174114] DOI:10.1310/tsr1406-22

115. Mahoney FI, Barthel DW. Functional evaluation: The Barthel Index. Md State Med J. 1965;14:61-65. [PMID: 14258950]
116. Kowalczewski JC, Chonq SL, Galea M, Prochazka A. Inhome tele-rehabilitation improves tetraplegic hand function. Neurorehabil Neural Repair. 2011 Mar 3. Available from: http://www.ncbi.nlm.nih.gov/pubmed?term=21372246

117. Lo AC, Guarino PD, Richards LG, Haselkorn JK, Wittenberg GF, Federman DG, Ringer RJ, Wagner TH, Krebs HI, Volpe BT, Bever CT Jr, Bravata DM, Duncan PW, Corn BH, Maffucci AD, Nadeau SE, Conroy SS, Powell JM, Huang GD, Peduzzi P. Robot-assisted therapy for longterm upper-limb impairment of stroke. N Engl J Med. 2010;362(19);1772-83. [PMID: 20400552] DOI:10.1056/NEJMoa0911341

118. Hanlon RE. Motor learning following unilateral stroke. Arch Phys Med Rehabil. 1996;77(8):811-15.

[PMID: 8702377] DOI:10.1016/S0003-9993(96)90262-2

119. Patton JL, Mussa-Ivaldi FA. Robot-assisted adaptive training: Custom force fields for teaching movement patterns. IEEE Trans Biomed Eng. 2004;51(4):636-46.

[PMID: 15072218$]$ DOI:10.1109/TBME.2003.821035

120. Pohl PS, McDowd JM, Filion D, Richards LG, Stiers W. Implicit learning of a motor skill after mild and moderate stroke. Clin Rehabil. 2006;20(3):246-53. [PMID: 16634344$]$ DOI:10.1191/0269215506cr916oa

121. Jebsen RH, Taylor N, Trieschmann RB, Trotter MJ, Howard LA. An objective and standardized test of hand function. Arch Phys Med Rehabil. 1969;50(6):311-19. [PMID: 5788487]

Submitted for publication April 5, 2010. Accepted in revised form August 29, 2010.

This article and any supplementary material should be cited as follows:

Scott SH, Dukelow SP. Potential of robots as next-generation technology for clinical assessment of neurological disorders and upper-limb therapy. J Rehabil Res Dev. 2011;48(4): 335-54.

DOI:10.1682/JRRD.2010.04.0057

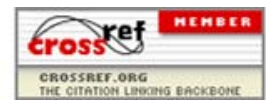


